\title{
Digital human designers
}

\author{
Gregory C. Smith*
}

CE Engineering, 1380 NE Airport Way,

Suite K79464, Portland, Oregon 97230, USA

E-mail: gsfsmith@msn.com

*Corresponding author

\section{Shana S. Smith}

Department of Mechanical Engineering,

National Taiwan University,

No. 1, Section 4, Roosevelt Road,

Taipei City, 10617, Taiwan

E-mail: ssmith@ntu.edu.tw

\begin{abstract}
This study creates digital human designers. Digital human designers are models of designers. Therefore, digital human designers use design methods to create designs. Digital human designers also use digital human users to create designs. Digital human users are models of users. Therefore, digital human designers use digital human users to determine the effects of designs on users. The digital human designers in this study created designs that matched user choices with $91.4 \%$ accuracies. As a result, the digital human designers in this study used design methods to fully automate the design process. The digital human designers in this study also used the digital human users in this study to determine the effects of designs on user structures. As a result, the digital human designers in this study also used the digital human users in this study to fully automate the design process.
\end{abstract}

Keywords: digital human designers; digital human models; design methods.

Reference to this paper should be made as follows: Smith, G.C. and Smith, S.S. (2015) 'Digital human designers', Int. J. Digital Human, Vol. 1, No. 1, pp.30-43.

Biographical notes: Gregory C. Smith is a Research Engineer at CE Engineering. His research interests include design methods, digital human models and robotics.

Shana S. Smith is a Professor in the Department of Mechanical Engineering at National Taiwan University. Her teaching and research interests include user-centred design, lifecycle design, engineering graphics, virtual reality and technology in education. 


\section{Introduction}

Real human designers use design methods to create designs. The design process consists of three steps: identify user needs, select design concepts and create designs. Therefore, real human designers use design methods to identify user needs, select design concepts and create designs. As a result, real human designers use design methods to partially automate the design process.

Real human designers also use digital human users to create designs. Digital human users are models of users. Therefore, digital human users are digital human models. Digital human users duplicate user behaviours, functions, or structures. Therefore, real human designers use digital human users to determine the effects of designs on users. As a result, real human designers also use digital human users to partially automate the design process.

Figure 1 shows that real human designers use design methods to create designs. Figure 1 shows that real human designers also use digital human users to create designs.

Figure 1 Real human designers

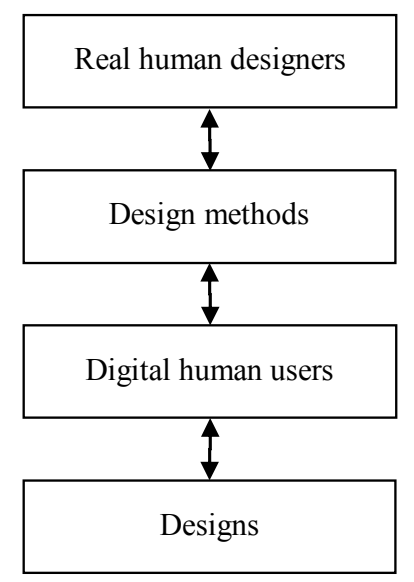

This study creates digital human designers. Digital human designers are models of designers. Therefore, digital human designers are digital human models. Digital human designers duplicate designer behaviours. Therefore, digital human designers use design methods to create designs. The design process consists of three steps: identify user needs, select design concepts and create designs. Therefore, digital human designers use design methods to identify user needs, select design concepts and create designs. As a result, digital human designers use design methods to fully automate the design process.

Digital human designers also use digital human users to create designs. Digital human users are models of users. Therefore, digital human users are digital human models. Digital human users duplicate user behaviours. Therefore, digital human designers use digital human users to determine the effects of designs on users. As a result, digital human designers also use digital human users to fully automate the design process.

Figure 2 shows that digital human designers use design methods to create designs. Figure 2 shows that digital human designers also use digital human users to create designs. 
Figure 2 Digital human designers

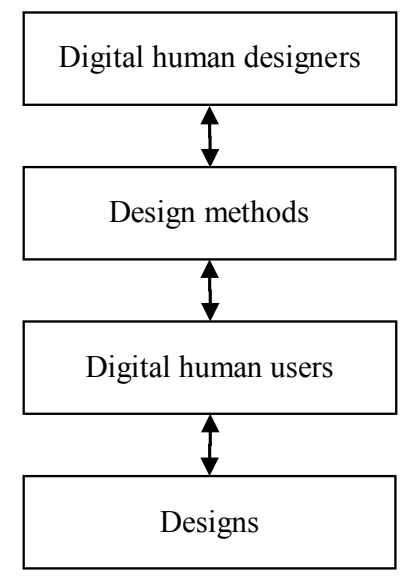

Digital human designers are new. Therefore, there are no previous studies on digital human designers. As a result, Section 2 uses concepts from previous studies on humans to create digital human designers, Section 3 uses concepts from previous studies on design methods to create designs, Section 4 uses concepts from previous studies on digital human users to determine the effects of designs on users and Section 5 presents results and conclusions.

The results and conclusions show that digital human designers are new. The results and conclusions show that digital human designers use design methods to fully automate the design process. The results and conclusions show that digital human designers also use digital human users to fully automate the design process.

\section{Digital human designers}

\subsection{Humans}

Humans use body, soul, and spirit components to sense, speak, and act, think, feel, and initiate, and consider, approve, and select. Body components use eye, ear, nose, mouth, and hand components to sense, speak, and act. Soul components use mind, emotion, and will components to think, feel, and initiate. Spirit components use fellowship, conscience, and intuition components to consider, approve, and select.

Figure 3 shows that humans use body, soul, and spirit components to sense, speak, and act, think, feel, and initiate, and consider, approve, and select.

Figure 3 Humans

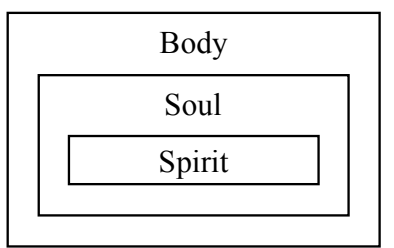




\subsection{Digital human designers}

Digital human designers are digital human models. Therefore, digital human designers use body, soul, and spirit modules to sense, speak, and act, think, feel, and initiate, and consider, approve, and select to create designs. Body modules use eye, ear, nose, mouth, and hand modules to sense, speak, and act to create designs. Soul modules use mind, emotion, and will modules to think, feel, and initiate to create designs. Spirit modules use fellowship, conscience, and intuition modules to consider, approve, and select to create designs.

Figure 4 shows that digital human designers use body, soul, and spirit modules to sense, speak, and act, think, feel, and initiate, and consider, approve, and select to create designs.

Figure 4 Digital human designers

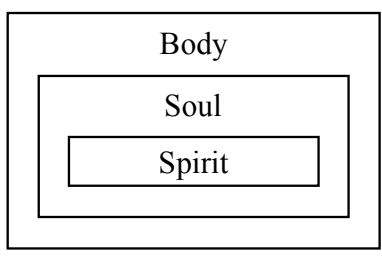

\subsection{The digital human designers in this study}

The digital human designers in this study were digital human models. Therefore, the digital human designers in this study used body, soul, and spirit modules to sense, speak, and act, think, feel, and initiate, and consider, approve, and select to create designs. The body modules used eye modules to sense to create designs. The soul modules used mind, emotion, and will modules to think, feel, and initiate to create designs. The spirit modules used fellowship, conscience, and intuition modules to consider, approve, and select to create designs.

The eye modules used document readers to process documents and extract text. The mind, emotion, and will modules used mind, emotion, and will rules to process text and extract aspirational, emotional, functional, and physical keywords. The fellowship, conscience, and intuition modules used fellowship, conscience, and intuition rules to process keywords and extract selected aspirational, emotional, functional, and physical keywords.

Figure 5 The digital human designers in this study

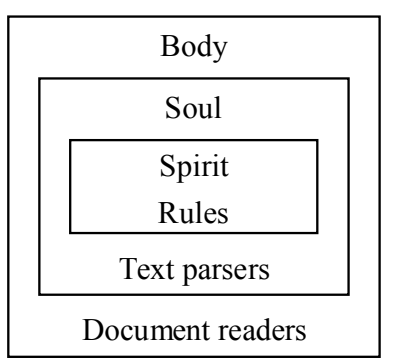


Figure 5 shows that the digital human designers in this study used document readers, mind, emotion, and will rules, and fellowship, conscience, and intuition rules to process documents and extract text, process text and extract aspirational, emotional, functional, and physical keywords, and process keywords and extract selected aspirational, emotional, functional, and physical keywords.

\section{Designs}

\subsection{The design methods in this study}

The digital human designers in this study were a design specification designer, a design selection designer, and a design configuration designer. Therefore, the digital human designers in this study used the latent semantic engineering design specification, design selection, and design configuration methods to identify user needs, select design concepts, and create designs.

The design specification designer used the latent semantic engineering design specification methods to match user choices to designs, match user needs to design concepts, and match design concepts to designs. The design selection designer used the latent semantic engineering design selection methods to match user choices to designs, and match user needs to designs. The design configuration designer used the latent semantic engineering design configuration methods to match user choices to designs.

Figure 6 shows that the digital human designers in this study used the latent semantic engineering design specification, design selection, and design configuration methods to create designs.

Figure 6 The design methods in this study

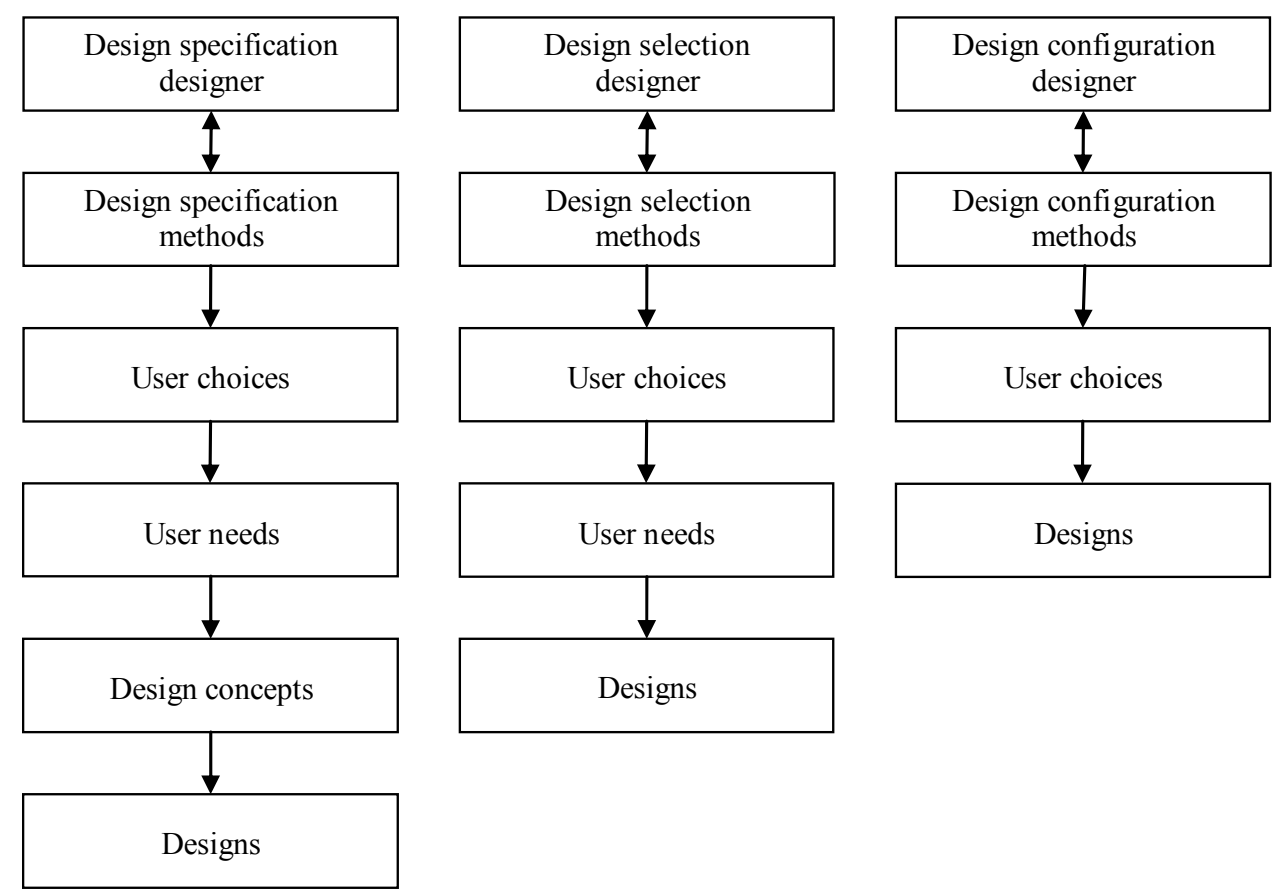




\subsection{The designs in this study}

The digital human designers in this study used the latent semantic engineering design specification, design selection, and design configuration methods to create 15 individually customised car designs for 15 users (one individually customised car design for each user). Fifteen of the users were from Taiwan, 15 of the users were 20-24 years old, 12 of the users were male, three of the users were female, and 15 of the users were graduate-level mechanical engineering students at a university.

The user choices were extracted from 15 design concept documents, which were chosen by users. The user needs were extracted from 15 user need documents, which were written by users. The design concepts were extracted from 100 design concept documents for Acura, Audi, BMW, Buick, Cadillac, Chevrolet, Chrysler, Dodge, Fiat, Ford, GMC, Honda, Hyundai, Infiniti, Jaguar, Jeep, Kia, Land Rover, Lexus, Lincoln, Mazda, Mercedes Benz, Mini, Mitsubishi, Nissan, Porsche, Scion, Smart, Subaru, Suzuki, Toyota, Volkswagen, and Volvo cars, trucks, suvs, and vans, which were written by reviewers from major newspapers, magazines, automotive websites, the US National Highway Traffic Safety Administration, and the US Insurance Institute for Highway Safety (U.S. News Best Cars). The designs were created from design elements, which were extracted from the 100 design concept documents. Therefore, the user choices, user needs, design concepts, and designs were represented by selected aspirational, emotional, functional, and physical keywords.

Table 1 The design concept document which was chosen by User 10

Mazda MX-5 Miata

$\{572$ words $\}$

The 2013 Mazda MX-5 Miata ranks 2 out of 10 affordable sports cars. This ranking is based on our analysis of published reviews and test drives of the Mazda MX-5 Miata, and our analysis of reliability and safety data.

The 2013 Mazda MX-5 Miata has a four-cylinder engine, which isn't as powerful as the engines of many sports cars in the class. However, test drivers agree that, combined with the Miata's light weight, the responsive engine delivers enough power to keep up with newer competitors like the Subaru BRZ. A five-speed manual transmission is standard, and test drivers love its short throws. Most also note that the transmission offers precise shifts that reinforce the Mazda Miata's fun driving dynamics. According to the EPA, the 2013 Miata gets up to 22/28 mpg city/highway, which is better than competitors like the Ford Mustang, but not quite as good as the Mini Cooper Roadster. In general, the automotive press loves the Miata's quick, accurate steering and athletic handling. In a comparison test, one reviewer also notes that the Miata soaks up bumps and road imperfections better than the BRZ. From a practical standpoint, the Miata also earns a better reliability rating than most cars in the class.

Inside, the Miata earns reviewer praise for its attractively-designed interior, which features a functional, driver-focused control layout. Most interior materials are hard plastic, but auto writers say that they're attractive and seem appropriate for the Miata's price. Some test drivers comment that the two-seat Miata's small size means that taller occupants may want more space. The Miata's trunk is also one of the smallest in the class, but some critics say that if you pack carefully, there's room for a weekend's worth of luggage. A few reviewers write that wind and road noise are common on the highway, even with the available hardtop. A six-speaker stereo with an auxiliary input jack is standard in the 2013 MX-5 Miata. Options and features available on higher trims include automatic climate control, leather seats, heated seats, Bluetooth, push-button start, satellite radio and a Bose stereo. 
Table 1 The design concept document which was chosen by User 10 (continued)

"This is the point at which I input the standard laudatory comments about the MX-5's excellent
handling, outstanding fun-to-drive factor, and fantastic value. And it's all true; very, very true.
I'm still convinced this is one of the best driver's cars on today's market." Consumer guide
"The Miata isn't flashy or fast. It's just a fun, affordable and reliable roadster that is guaranteed
to bring a smile to the face of anyone with a beating heart and a valid driver's license."
Kelley Blue Book
"This compact convertible offers everything a driver needs - style, convenience and ample fun."
AutoWeek (2011)
The 2013 Mazda MX-5 Miata is a rear-wheel drive, two-seat convertible that's available with a
soft top or a retractable hardtop. A 2.0-liter four-cylinder engine and a five-speed manual
transmission come standard, and a six-speed automatic transmission is optional. The Miata comes
in three trims: sport, club and grand touring. Club and grand touring trims add to the Miata's list
of interior features, and come with a six-speed manual transmission as standard equipment. For
2013 , the Miata gets an updated front fascia and standard fog lights, and the Club trim replaces
the outgoing Touring model. Aside from that, the Miata is basically unchanged. As a result, this
overview uses applicable research and reviews from 2007 through 2012, as well as the current
model year.

Table 2 The user need document which was written by User 10

\section{User 10}

$\{95$ words $\}$

I would like the car which has scissors doors. Automatic transmission is a trend, it can let more people drive this car. And if car makes available in the convertible category, I can enjoy going for a spin. Car's drive train would better be rear-wheel drive for a good drive control. The cabriolet makes people feel more luxury about the car. It would be better to be a hybrid car, which make less carbon dioxide and use electricity instead of fuel, for being green. The price of car must be low, that people can afford it.

Table 3 The design concept document for the Mazda MX-5 Miata

\section{Mazda MX-5 Miata}

$$
\{572 \text { words }\}
$$

The 2013 Mazda MX-5 Miata ranks 2 out of 10 affordable sports cars. This ranking is based on our analysis of published reviews and test drives of the Mazda MX-5 Miata, and our analysis of reliability and safety data.

The 2013 Mazda MX-5 Miata has a four-cylinder engine, which isn't as powerful as the engines of many sports cars in the class. However, test drivers agree that, combined with the Miata's light weight, the responsive engine delivers enough power to keep up with newer competitors like the Subaru BRZ. A five-speed manual transmission is standard, and test drivers love its short throws. Most also note that the transmission offers precise shifts that reinforce the Mazda Miata's fun driving dynamics. According to the EPA, the 2013 Miata gets up to 22/28 mpg city/highway, which is better than competitors like the Ford Mustang, but not quite as good as the Mini Cooper Roadster. In general, the automotive press loves the Miata's quick, accurate steering and athletic handling. In a comparison test, one reviewer also notes that the Miata soaks up bumps and road imperfections better than the BRZ. From a practical standpoint, the Miata also earns a better reliability rating than most cars in the class. 
Table 3 The design concept document for the Mazda MX-5 Miata (continued)

\begin{abstract}
Inside, the Miata earns reviewer praise for its attractively-designed interior, which features a functional, driver-focused control layout. Most interior materials are hard plastic, but auto writers say that they're attractive and seem appropriate for the Miata's price. Some test drivers comment that the two-seat Miata's small size means that taller occupants may want more space. The Miata's trunk is also one of the smallest in the class, but some critics say that if you pack carefully, there's room for a weekend's worth of luggage. A few reviewers write that wind and road noise are common on the highway, even with the available hardtop. A six-speaker stereo with an auxiliary input jack is standard in the 2013 MX-5 Miata. Options and features available on higher trims include automatic climate control, leather seats, heated seats, Bluetooth, push-button start, satellite radio and a Bose stereo.

"This is the point at which I input the standard laudatory comments about the MX-5's excellent handling, outstanding fun-to-drive factor, and fantastic value. And it's all true; very, very true. I'm still convinced this is one of the best driver's cars on today's market." Consumer guide

"The Miata isn't flashy or fast. It's just a fun, affordable and reliable roadster that is guaranteed to bring a smile to the face of anyone with a beating heart and a valid driver's license." Kelley Blue Book

"This compact convertible offers everything a driver needs - style, convenience and ample fun." AutoWeek (2011)

The 2013 Mazda MX-5 Miata is a rear-wheel drive, two-seat convertible that's available with a soft top or a retractable hardtop. A 2.0-liter four-cylinder engine and a five-speed manual transmission come standard, and a six-speed automatic transmission is optional. The Miata comes in three trims: sport, club and grand touring. Club and grand touring trims add to the Miata's list of interior features, and come with a six-speed manual transmission as standard equipment. For 2013, the Miata gets an updated front fascia and standard fog lights, and the Club trim replaces the outgoing Touring model. Aside from that, the Miata is basically unchanged. As a result, this overview uses applicable research and reviews from 2007 through 2012, as well as the current model year.
\end{abstract}

Table 4 The user choice keywords for User 10

Mazda MX-5 Miata

$\{94$ keywords $\}$

type-Mazda-MX-5, type-affordable-sports-car, type-convertible, type-sports-car, rank-affordablesports-car-2, rank-affordable-sports-car-high, rank-affordable-convertible-1, rank-affordableconvertible-high, price-23720-30350, price-affordable, mpg-city-22, mpg-hwy-28, mpg-cityhigh-not, mpg-hwy-high-not, fuel-efficient-not, performance-9.0, performance-high, interior-6.0, interior-high-not, safety-na, safety-high-not, lights-fog, front-updated, handling-high, handlingsuperb, top-hard, top-retractable, reliability-high, interior-space-not, trunk-large-not, performance-spirited, engine-4c, engine-powerful-not, weight-light, engine-responsive, powercompetitive, speeds-5, transmission-manual, transmission-precise, transmission-high, type-fun, fuel-competitive, steering-responsive, steering-accurate, steering-high, handling-high, handlingathletic, ride-smooth, reliability-high, reliability-competitive, interior-attractive, interface-high, interface-easy, interior-materials, interior-plastic, persons-2, size-small, interior-space-not, trunklarge-not, ride-quiet-not, top-noise-not, stereo-has, stereo-6-speaker, audio-input, climate-control, seats-leather, seats-heated, bluetooth-has, start-automatic, radio-has, radio-satellite, stereo-Bose, handling-high, type-fun, price-value, speed-high-not, reliability-high, type-unchanged-not, typestylish, type-convenient, type-rwd, persons-2, top-soft, top-hard, top-retractable, engine-2.0-liter, engine-4c, speeds-5, transmission-manual, speeds-6, transmission-auto, front-updated, lights-fog, type-unchanged 
Table 5 The user need keywords for User 10

\section{Subject 10 \\ $\{17$ keywords $\}$}

doors-high, doors-scissor, transmission-high, transmission-auto, type-convertible, ride-high, rideenjoyable, type-rwd, handling-high, handling-control, type-luxury, type-hybrid, earth-protect, emissions-low, type-electric, fuel-efficient, price-affordable

Table 6 The design concept keywords for the Mazda MX-5 Miata

\section{Mazda MX-5 Miata}

$\{94$ keywords\}

type-Mazda-MX-5, type-affordable-sports-car, type-convertible, type-sports-car, rank-affordablesports-car-2, rank-affordable-sports-car-high, rank-affordable-convertible-1, rank-affordableconvertible-high, price-23720-30350, price-affordable, mpg-city-22, mpg-hwy-28, mpg-cityhigh-not, mpg-hwy-high-not, fuel-efficient-not, performance-9.0, performance-high, interior-6.0, interior-high-not, safety-na, safety-high-not, lights-fog, front-updated, handling-high, handlingsuperb, top-hard, top-retractable, reliability-high, interior-space-not, trunk-large-not, performance-spirited, engine-4c, engine-powerful-not, weight-light, engine-responsive, powercompetitive, speeds-5, transmission-manual, transmission-precise, transmission-high, type-fun, fuel-competitive, steering-responsive, steering-accurate, steering-high, handling-high, handlingathletic, ride-smooth, reliability-high, reliability-competitive, interior-attractive, interface-high, interface-easy, interior-materials, interior-plastic, persons-2, size-small, interior-space-not, trunklarge-not, ride-quiet-not, top-noise-not, stereo-has, stereo-6-speaker, audio-input, climate-control, seats-leather, seats-heated, bluetooth-has, start-automatic, radio-has, radio-satellite, stereo-Bose, handling-high, type-fun, price-value, speed-high-not, reliability-high, type-unchanged-not, typestylish, type-convenient, type-rwd, persons-2, top-soft, top-hard, top-retractable, engine-2.0-liter, engine-4c, speeds-5, transmission-manual, speeds-6, transmission-auto, front-updated, lights-fog, type-unchanged

Table 1 shows the design concept document which was chosen by User 10. Table 2 shows the user need document which was written by User 10. Table 3 shows the design concept document for the Mazda MX-5 Miata. Table 4 shows the 94 user choice keywords which were extracted for User 10. Table 5 shows the 17 user need keywords which were extracted for User 10. Table 6 shows the 94 design concept keywords which were extracted for the Mazda MX-5 Miata. For all of the user choices, user needs, and design concepts, there were 553 user choice, user need, and design concept keywords.

The 553 user choice, user need, and design concept keywords were used to create 553 -element user choice, user need, and design concept vectors. The 94 user choice keywords for User 10 were used to create a 553-element user choice vector with 459 zeros and 94 ones, the 17 user need keywords for User 10 were used to create a 553-element user need vector with 536 zeros and 17 ones, and the 94 design concept keywords for the Mazda MX-5 Miata were used to create a 553-element design concept vector with 459 zeros and 94 ones.

The user choice, user need, and design concept vectors were projected into a latent semantic engineering semantic space. The projected vectors were matched by calculating latent semantic engineering semantic space cosines. The projected vectors with the lowest latent semantic engineering semantic space cosines were the closest matches (Smith and Smith, 2012).

For the design specification designer, the projected vectors were matched to match user choices to designs, match user needs to design concepts, and match design concepts 
to designs. For the design selection designer, the projected vectors were matched to match user choices to designs, and match user needs to designs. For the design configuration designer, the projected vectors were matched to match user choices to designs, and match (user-selected) design concepts to designs.

\subsection{The design accuracies in this study}

The design accuracies in this study were the number of vector elements that matched divided by 553 (the total number of vector elements). The design accuracies for the latent semantic engineering design specification method were |UCDA| (user choice to design accuracy), UNDA (user need to design accuracy), UNCA (user need to design concept accuracy), and DCDA (design concept to design accuracy). The design accuracies for the latent semantic engineering design selection method were $|\mathrm{UCDA}|$ (user choice to design accuracy), and UNDA (user need to design accuracy). The design accuracies for the latent semantic engineering design configuration method were $|\mathrm{UCDA}|$ (user choice to design accuracy), and DCDA (design concept to design accuracy).

Table 7 The design accuracies in this study

\begin{tabular}{lccccc}
\hline Results & Designer & $|U C D A|$ & UNDA & UNCA & DCDA \\
\hline$(1)$ & Specification & 91.4 & 90.7 & 90.7 & 100.0 \\
$(2)$ & Selection & 97.2 & 95.8 & & \\
$(3)$ & Configuration & 100.0 & & & 100.0 \\
\hline
\end{tabular}

Table 7 shows the design accuracies for the three digital human designers and the 15 individually customised car designs in this study. The design accuracies show that the design specification designer created designs from user need documents, the design selection designer created designs from user need documents, and the design configuration designer created designs from (user-selected) design concept documents. The design accuracies show that the design specification designer created individually customised car designs that matched user choices and user needs with 91.4 and $90.7 \%$ accuracies, the design selection designer created individually customised car designs that matched user choices and user needs with 97.2 and $95.8 \%$ accuracies, and the design configuration designer created individually customised car designs that matched user choices and (user-selected) design concepts with 100.0 and $100.0 \%$ accuracies. As a result, the design accuracies show that the digital human designers in this study used the latent semantic engineering design specification, design selection, and design configuration methods to fully automate the design process.

\section{Digital human users}

\subsection{The digital human users in this study}

The digital human users in this study were structural models of users. Therefore, the digital human users in this study were digital human models. The digital human users in this study duplicated the structures (heights) of users. Therefore, the digital human designers in this study used the digital human users in this study to determine the effects of individually customised car designs (headroom) on user structures (fit). As a result, the 
digital human designers in this study also used the digital human users in this study to fully automate the design process.

\section{Conclusions}

\subsection{This study}

This study creates digital human designers. The digital human designers in this study were a design specification designer, a design selection designer, and a design configuration designer. Therefore, the digital human designers in this study used the latent semantic engineering design specification, design selection, and design configuration methods to identify user needs, select design concepts, and create designs. As a result, the digital human designers in this study used the latent semantic engineering design specification, design selection, and design configuration methods to fully automate the design process.

The design accuracies show that the design specification designer created individually customised car designs that matched user choices and user needs with 91.4 and $90.7 \%$ accuracies, the design selection designer created individually customised car designs that matched user choices and user needs with 97.2 and $95.8 \%$ accuracies, and the design configuration designer created individually customised car designs that matched user choices and (user-selected) design concepts with 100.0 and $100.0 \%$ accuracies.

The digital human designers in this study also used the digital human users in this study to determine the effects of individually customised car designs (headroom) on user structures (fit). As a result, the digital human designers in this study also used the digital human users in this study to fully automate the design process.

\subsection{Future studies}

The digital human designers in future studies can use complete body, soul, and spirit modules to sense, speak, and act, think, feel, and initiate, and consider, approve, and select to create designs. The body modules in future studies can use eye, ear, nose, mouth, and hand modules to sense, speak, and act to create concepts, designs, and prototypes. The soul modules in future studies can use mind, emotion, and will modules to think, feel, and initiate to create concepts, designs, and prototypes. The spirit modules in future studies can use fellowship, conscience, and intuition modules to consider, approve, and select to create concepts, designs, and prototypes.

The digital human designers in future studies can be design specification designers, design selection designers, and design configuration designers. Therefore, the digital human designers in future studies can use the latent semantic engineering, Kansei engineering - latent semantic analysis, Kansei Engineering, conjoint analysis, or quality function deployment design specification, design selection, and design configuration methods to identify user needs, select design concepts, and create designs. As a result, the digital human designers in future studies can use the latent semantic engineering, Kansei engineering - latent semantic analysis, Kansei engineering, conjoint analysis, or quality function deployment design specification, design selection, and design configuration methods to fully automate the design process (Akao and Ishihara, 1994; Deming, 1980, 
2000; Green and Rao, 1971; Nagamachi, 1974, 1989, 1995, 2002; Smith and Smith, 2011, 2012; Smith et al., 2013).

The digital human users in future studies can be behavioural, functional, or structural models of users. Therefore, the digital human users in future studies can be digital human models. The digital human users in future studies can duplicate the behaviours, functions, or structures of users. Therefore, the digital human designers in future studies can use the digital human users in future studies to determine the effects of individually customised designs on user behaviours, functions, or structures. As a result, the digital human designers in future studies can also use the digital human users in future studies to fully automate the design process (Bekey, 1998; Bicego, 2005; Carruth et al., 2007; Choi et al., 2008; De Magistris et al., 2013; Demirel and Duffy, 2007a, 2007b; Hardy et al., 1984; Hsu and Chen, 2012; Ishihara et al., 2005; Jung et al., 2009; Kao and Smith, 2011; Kuffner et al., 2003; Li and Zhang, 2007; Liu et al., 2010; Lu and Smith, 2006; Lu et al., 2010; Maldonado-Bascon, 2007; May et al., 2011; Miller et al., 2010; Minami et al., 1994; Noble et al., 2012; Oguri et al., 2000; Rohrer, 2007; Smith and Smith, submitted; Smith and Yen, 2010; Smith et al., 2012a, 2012b; Taish et al., 2011; Tokuda et al., 1998; van den Broek, 2010; Zhang and Tan, 2013; Zimmer and Miteran, 2001).

\section{References}

Akao, Y. and Ishihara, K. (1994) Development History of Quality Function Deployment. The Customer Driven Approach to Quality Planning and Deployment, APO, Tokyo.

Bekey, G. (1998) 'On autonomous robots', The Knowledge Engineering Review, Vol. 13, No. 2, pp.143-146.

Bicego, M. (2005) 'Odor classification using similarity-based representation', Sensors and Actuators, Vol. B 100, No. 2, pp.225-230.

Carruth, D., Thomas, M, Robbins, B. and Morais, A. (2007) 'Integrating perception, cognition, and action for digital human modeling', Lecture Notes in Computer Science, Vol. 4561, pp.333-342.

Choi, J., Son, H. and Lee, Y. (2008) 'Design of a biomimetic robot-eye system with single vari-focal lens and winding-type SMA actuator', International Conference on Control, Automation, and Sustems, pp.2533-2537.

De Magistris, G., Micaelli, A., Evrard, P., Andriot, C., Savin, J., Gaudez, C. and Marsot, J. (2013) 'Dynamic control of DHM for ergonomic assessments', International Journal of Industrial Ergonomics, Vol. 43, No. 2, pp.170-180.

Deming, W. (1980) 'Quality in Japan', Conference Nationale AFCIQ, Paris, pp.1-3.

Deming, W. (2000) Out of the Crisis, MIT Press, Cambridge.

Demirel, H. and Duffy, V. (2007a) 'Applications of digital human modeling in industry', Lecture Notes in Computer Science, Vol. 4561, pp.824-832.

Demirel, H. and Duffy, V. (2007b) 'Digital human modeling for product lifecycle management', Lecture Notes in Computer Science, Vol. 4561, pp.372-381.

Green, P. and Rao, V. (1971) 'Conjoint measurement for quantifying judgmental data', Journal of Market Research, Vol. 8, No. 3, pp.355-363.

Hardy, H., Collins, R. and Calvert, R. (1982) 'A digital computer model of the human circulatory system', Medical and Biological Engineering and Computing, Vol. 20, No. 5, pp.550-564.

Hsu, C. and Chen, C. (2012) 'Speaker-dependent model interpolation for statistical emotional speech synthesis', European Association for Signal Processing Journal on Audio, Speech, and Music Processing, No. 1, pp.1-10. 
Ishihara, S., Ikeda, A., Citterio, D., Maruyama, K., Hagiwara, M. and Suzuki, K. (2005) 'Smart chemical taste sensor for determination and prediction of taste qualities based on a two-phase optimized radial basis function network', Analytical Chemistry, Vol. 77, No. 24, pp.7908-7915.

Jung, K., Kwon, O. and You, H. (2009) 'Development of a digital human model generation method for ergonomic design in virtual environments', International Journal of Industrial Ergonomics, Vol. 39, No. 5, pp.744-748.

Kao, Y. and Smith, S. (2011) 'Dynamic tracking of infrared points in a three-dimensional space', International CAD Conference and Exhibition, Paper No. 105.

Kuffner, J., Nishiwaki, K., Kagami, S., Inaba, M. and Inoue, H. (2003) 'Motion planning for humanoid robots', International Symposium of Robotics Research, pp.1-10.

Li, K. and Zhang, X. (2007) 'The strength factor in digital human modeling and simulation: a case for a new framework', Lecture Notes in Computer Science, Vol. 4561, pp.144-146.

Liu, Q., Ye, W., Hu, N., Cai, H., Yu, H. and Wang, P. (2010) 'Olfactory receptor cells respond to odors in a tissue and semiconductor hybrid neuron chip', Biosensors and Bioelectronics, Vol. 26, No. 4, pp.1672-1678.

Lu, J., Wang, M., Chen, C. and Wu, J. (2010) 'The development of an intelligent system for customized clothing making', Expert Systems with Applications, Vol. 37, No. 1, pp.799-803.

Lu, Y. and Smith, S. (2006) 'A comprehensive tool for recovering 3D models from 2D photos', Journal of Computing and Information Science in Engineering, Vol. 6, No. 4, pp.372-380.

Maldonado-Bascon, S., Lafuente-Arroyo, S., Gil-Jiménez, P., Gomez-Moreno, H. and Lopez-Ferreras, F. (2007) 'Road-sign detection and recognition based on support vector machines', IEEE Transactions on Intelligent Transportation Systems, Vol. 8, No. 2, pp.264-278.

May, T., van de Par, S. and Kohlrausch, A. (2011) 'A probabilistic model for robust localization based on binaural auditory front-end', IEEE Transactions on Acoustics, Speech, and Language Processing, Vol. 18, No. 1, pp.1-13.

Miller, A., Marsh, J., Reeve, A., Garny, A., Britten, R., Halstead, M., Cooper, J., Nickerson, D. and Nielsen, P. (2010) 'An overview of the CellML API and its implementation', $B M C$ Bioinformatics, Vol. 11, No. 178, pp.1-12.

Minami, Y., Shikano, K., Takahashi, S., Yamada, T., Yoshioka, O. and Furui, S. (1994) 'A largevocabulary continuous speech recognition algorithm applied to a multi-modal telephone directory assistance system', Speed Communication, Vol. 15, Nos. 3-4, pp.301-310.

Nagamachi, M. (1974) 'A study of emotional technology', Japanese Journal of Ergonomics, Vol. 10, No. 2, pp.121-130.

Nagamachi, M. (1989) Kansei Engineering, Kaibundo Publishing, Tokyo.

Nagamachi, M. (1995) 'Kansei engineering: a new ergonomic consumer-oriented technology for product development', International Journal of Industrial Ergonomics, Vol. 15, No. 1, pp.3-11.

Nagamachi, M. (2002) 'Kansei engineering as a powerful consumer-oriented technology for product development', Applied Ergonomics, Vol. 33, No. 3, pp.289-294.

Noble, D., Garny, A. and Noble, P. (2012) 'How the Hodgkin-Huxley equations inspired the cardiac physiome project', Journal of Physiology, Vol. 590, No. 11, pp.2613-2628.

Oguri, K., Sugimoto, T. and Iwata, A. (2000) 'A gustatory information processing model for the evaluation of taste preference', International Joint Conference on Neural Networks, Vol. 1, pp.234-239.

Rohrer, B. (2007) 'S-learning: a biomimetic algorithm for learning, memory, and control in robots', IEEE Conference on Neural Engineering, pp.148-151.

Smith, G. and Smith, S. (2011) Method for Recognizing Objects in Images, US Patent: 2011/0081081, 1-17. 
Smith, G. and Smith, S. (submitted) 'Digital human models', International Journal of the Digital Human

Smith, G. and Smith, S. (2012) 'Latent semantic engineering - a new conceptual user-centered design approach', Advanced Engineering Informatics, Vol. 26, No. 2, pp.456-473.

Smith, S. and Yen, C. (2010) 'Green product design through product modularization using atomic theory', Robotics and Computer-Integrated Manufacturing, Vol. 26, No. 6, pp.790-798.

Smith, S., Smith, G. and Chen, W. (2012a) 'Disassembly sequence structure graphs: an optimal approach for multiple-target selective disassembly sequence planning', Advanced Engineering Informatics, Vol. 26, No. 2, pp.306-316.

Smith, S., Smith, G. and Chen, Y. (2013) 'A KE-LSA approach for user-centered design', Journal of Intelligent Manufacturing, Vol. 24, No. 5, pp.919-933.

Smith, S., Smith, G. and Lee, J. (2012b) 'A realistic portable tactile haptic device', Proceedings of TMCE 2012, pp.7-11.

Taish, M., Cammarino, B. and Cassina, J. (2011) 'Lifecycle data management: first step towards a new product lifecycle management standard', International Journal of Computer Integrated Manufacturing, Vol. 24, No. 12, pp.1117-1135.

Tokuda, K., Masuko, T., Hiroi, J., Kobayashi, T. and Kitamura, T. (1998) 'A very low bit rate speech coder using HMM-based speech recognition/synthesis techniques', International Conference on Acoustics, Speech and Signal Processing, Vol. 2, pp.609-612.

U.S. News Best Cars [online] http://usnews.rankingsandreviews.com/cars-trucks/.

van den Broek, E. (2010) 'Beyond biometrics', International Conference on Computational Science, pp.2511-2519.

Zhang, X. and Tan, C. (2013) 'Handwritten word image matching based on heat kernel signature', Lecture Notes in Computer Science, Vol. 8048, No. 2, pp.42-49.

Zimmer, J. and Miteran, J. (2001) 'Face modeling: a real-time embedded implementation of a stereovision algorithm', Proceedings of the SPIE, pp.155-162. 